\title{
Adverse Skin Reactions due to Ribavirin in Hepatitis C Combination Therapy with Pegylated Interferon- $\alpha_{2 a}$
}

\author{
Masahisa Shindo ${ }^{a}$ Isamu Terai ${ }^{b}$ \\ a'Department of Dermatology, National Hospital Organization Hamada Medical Center,

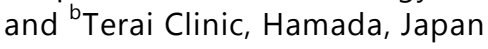

\section{Key Words}

Ribavirin · Hepatitis C · Drug eruption - Lymphocyte transformation test

\begin{abstract}
The introduction of ribavirin to hepatitis $C$ combination therapy with pegylated interferon (PEG-IFN)- $\alpha_{2 a}$ has improved sustained responses, but it has been accompanied by an increased incidence of cutaneous side effects. Most cases of drug eruption caused by ribavirin and PEG-IFN- $\alpha_{2}$ or IFN- $\alpha$ combination therapy were not severe and we progressed without discontinuation of the antiviral treatment. We describe a 59-year-old Japanese woman with a chronic hepatitis $C$ infection who developed erythema during PEG-IFN- $\alpha_{2 a}$ and ribavirin combination therapy. The eruption at the injection site of IFN occurred after each injection, and then, eruption on her exposed skin was observed. Twenty milligrams of prednisolone was administered. The eruption recurred after each administration of prednisolone and ribavirin. She finally had infiltrative erythema without any mucosal symptoms on her body. It seemed to be an erythema multiforme type drug eruption of PEGIFN- $\alpha_{2 a}$, ribavirin and/or fluvastatin sodium from the clinical course. The lymphocyte transformation test (LTT) of ribavirin was positive. This is the first case of a positive result of an LTT for ribavirin. A photosensitive type drug eruption with ribavirin treatment has been reported. We should not only consider IFN, but also ribavirin in case of a generalized eruption, especially on an exposed area with combination therapy for HCV.
\end{abstract}




\section{Introduction}

The introduction of ribavirin to hepatitis $\mathrm{C}$ combination therapy with pegylated interferon (PEG-IFN)- $\alpha_{2 a}$ has improved sustained clinical response rates, but it has been accompanied by an increased incidence of cutaneous side effects. There has been 1 prospective study on the de novo onset of skin symptoms associated with PEG-IFN- $\alpha_{2 a}$ and ribavirin combination treatment [1], and there have been some reports of drug eruption caused by ribavirin and PEG-IFN- $\alpha_{2 b}[2,3]$ or IFN- $\alpha$ combination therapy $[4,5]$. Most cases were not severe and improved only with a topical steroid and oral anti-allergic drug, without the need for discontinuation of the antiviral treatment. Severe cases required a discontinuation of the antiviral treatment [3-5]; a steroid was administered in very severe cases [2,3].

\section{Case Report}

We describe a 59-year-old Japanese woman with a chronic hepatitis C infection who developed erythema during PEG-IFN- $\alpha_{2 a}$ and ribavirin therapy. There was a faint erythema on her trunk and her arms after 8 weeks of treatment (week 8). Administration of bepotastine besilate had no effect. However, the erythema improved with the application of crotamiton cream and alclometasone dipropionate ointment. Fluvastatin sodium was added for her hypercholesterolemia at week 12. The HCV RNA virus had decreased from 6.6 $\log \mathrm{IU} / \mathrm{ml}$ to negative at week 16 . Subcutaneous injection of PEG-IFN- $\alpha_{2 a}$ was postponed due to recurrent erythema at week 20. Eruption at the injection site of IFN occurred after each injection, and then, eruption on her head, face and neck (exposed skin) was observed (fig. 1). Twenty milligrams of prednisolone was administered. After each administration of prednisolone and ribavirin, the eruption recurred. The eruption consisted of red papules fused to an erythematous plaque. After PEG-IFN- $\alpha_{2 a}$ subcutaneous injection in her right arm, the eruptions became worse and she had a consultation in our department. At that time, she had infiltrative erythema without any mucosal symptoms on her whole body (fig. 1). It seemed to be an erythema multiforme type drug eruption of PEG-IFN- $\alpha_{2 a}$, ribavirin and/or fluvastatin sodium from the clinical course. Although administration of all drugs was stopped, the eruption expanded after administering $40 \mathrm{mg}$ prednisolone and a topical steroid. Since prednisolone was suspected to have been the cause of the drug eruption, the eruption improved after it was changed to $6 \mathrm{mg}$ of betamethasone.

The HCV RNA virus was negative at week 17. However, it had increased to $6.8 \log \mathrm{IU} / \mathrm{ml}$ at week 28.

The lymphocyte transformation test (LTT) was carried out for PEG-IFN- $\alpha_{2 a}$, ribavirin and fluvastatin sodium. Only ribavirin was positive.

\section{Discussion}

This is the first case of a positive result after performing the LTT for ribavirin. Activation of drug-specific T-cells is generally thought to play a central role in mediating adverse drug reactions. The LTT is a safety test to assess the activation of drug-specific T-cells in vitro and is a reliable method to define the causative agent [6]. The LTT measures the proliferation of T-cells to a drug in vitro from which 1 concludes to a previous in vivo reaction due to a sensitization. This concept of the LTT has been confirmed by the generation of drug-specific $\mathrm{T}$-cell clones and the finding that drugs can directly interact with the T-cell receptor, without 
Shindo et al.: Adverse Skin Reactions due to Ribavirin in Hepatitis C Combination Therapy with Pegylated Interferon- $\alpha_{2 a}$

any previous metabolism or the need to bind to proteins. The main advantage of this test is its applicability with many different drugs in different immune reactions, as drug-specific Tcells are almost always involved in drug hypersensitivity reactions [7].

In our case, an eruption at the injection site of IFN occurred every time after the injection. Then eruption on her head, face and neck (exposed skin) was seen. A photosensitivetype drug eruption with ribavirin treatment has been reported [4]. We should not only consider IFN, but also ribavirin in case of generalized eruption, especially on an exposed area, with combination therapy for HCV.

\section{References}

-1 Lübbe J, Kerl K, Negro F, Saurat JH: Clinical and immunological features of hepatitis C treatment-associated dermatitis in 36 prospective cases. Br J Dermatol 2005;153:1088-1090.

-2 Hashimoto Y, Kanto H, Itoh M: Adverse skin reactions due to pegylated interferon alpha $2 \mathrm{~b}$ plus ribavirin combination therapy in a patient with chronic hepatitis C virus. J Dermatol 2007;34:577-582.

-3 Cottoni F, Bolognini S, Deplano A, Garrucciu G, Manzoni NE, Careddu GF, Montesu MA, Tocco A, Lissia A, Solinas A: Skin reaction in antiviral therapy for chronic hepatitis C: a role for polyethylene glycol interferon? Acta Derm Venereol 2004;84:120-123.

-4 Savk E, Uslu G, Karaoğlu AO, Sendur N, Karaman G: Diffuse cutaneous eruption due to interferon alfa and ribavirin treatment of chronic hepatitis C. J Eur Acad Dermatol Venereol 2005;19:396-398.

5 Okai T, Shirasaki F, Sawabu N: Erythematous maculopapular eruption due to ribavirin administration in a patient with chronic hepatitis C. J Clin Gastroenterol 2003;36:283-284.

-6 Kano Y, Hirahara K, Mitsuyama Y, Takahashi R, Shiohara T: Utility of the lymphocyte transformation test in the diagnosis of drug sensitivity: dependence on its timing and the type of drug eruption. Allergy 2007;62:1439-1444.

7 Pichler WJ, Tilch J: The lymphocyte transformation test in the diagnosis of drug hypersensitivity. Allergy 2004;59:809-820.

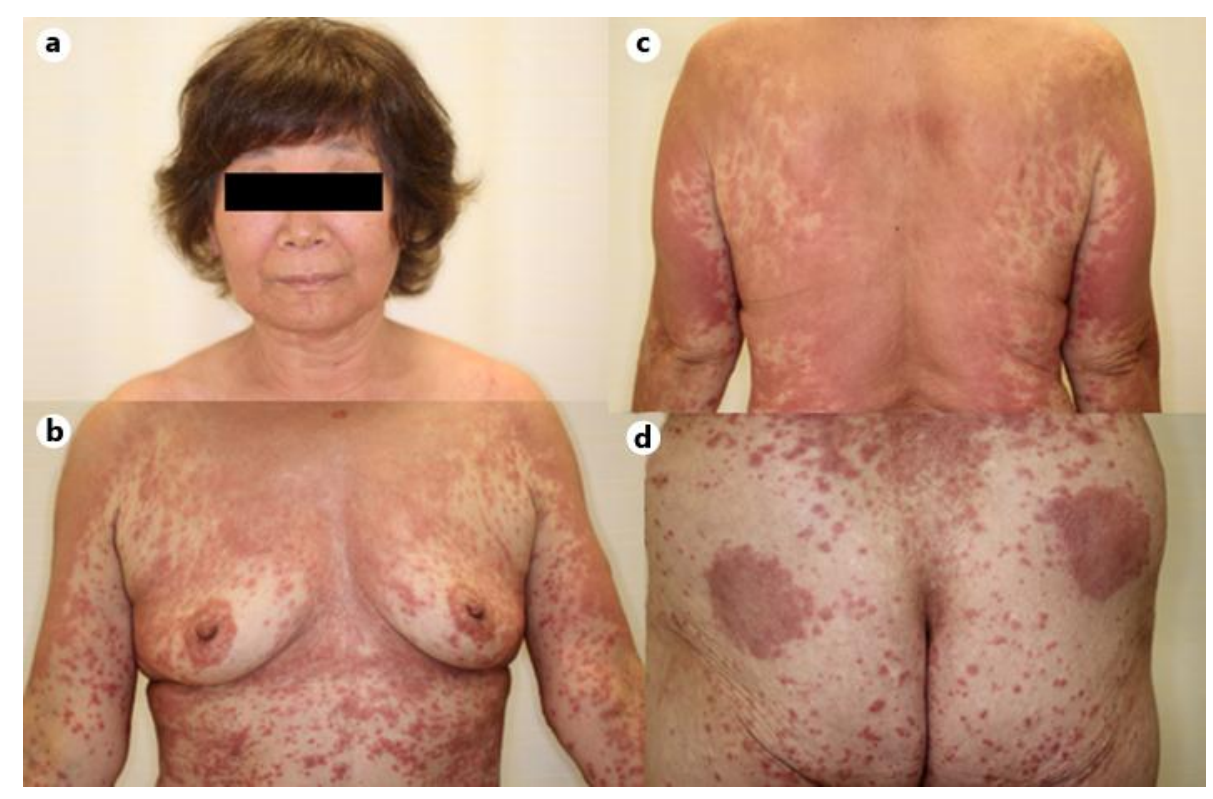

Fig. 1. Pruritic erythematous eruption located on the face and neck (a), chest (b) and back (c). On the buttock, erythematous plaques at the injection site are visible (d). 